\title{
COPPER ELECTRODEPOSITION ON GLASSY CARBON AND HIGHLY ORIENTED PYROLYTIC GRAPHITE SUBSTRATES FROM PERCHLORATE SOLUTIONS
}

\author{
Diana Elizabeth García-Rodríguez and Luis Humberto Mendoza-Huizar* \\ Área Académica de Química, Universidad Autónoma del Estado de Hidalgo, CP. 42186 Mineral de la Reforma, Hidalgo, México \\ Clara Hilda Rios-Reyes \\ Área Académica de Ciencias de la Tierra y Materiales, Universidad Autónoma del Estado de Hidalgo, CP. 42186 Mineral de la \\ Reforma, Hidalgo, México \\ Martín Alejandro Alatorre-Ordaz \\ Departamento de Química, Universidad de Guanajuato, CP. 36040, Guanajuato, Mexico
}

Recebido em 28/4/11; aceito em 31/10/11; publicado na web em 20/12/11

\begin{abstract}
In present work, we analyzed the copper electrodeposition onto GCE (System I) and HOPGE (System II) from perchlorate solutions. The current density transients obtained from system I and II were well described through a kinetic mechanism that involves four different contributions: (a) a Langmuir type adsorption process, b) an electron transfer from $\mathrm{Cu}^{2+} \rightarrow \mathrm{Cu}^{+}$, (c) a 3D nucleation limited by a mass transfer reaction and (d) a proton reduction process. It was observed that the values of the nucleation rate, the number of active nucleation sites were increased with the overpotential and they are bigger onto GCE in comparison with HOPGE.
\end{abstract}

Keywords: copper; nucleation; proton reduction.

\section{INTRODUCTION}

Copper electrodeposition process represents a very attractive and inexpensive via to get copper surfaces which may be employed in the fabrication of interconnects and printed circuit boards because they exhibit high conductivity. Copper electrodeposition has been studied on numerous substrates including glassy carbon, ${ }^{1-7}$ highly oriented pyrolytic graphite, ${ }^{8-10}$ polycrystalline and single-crystal $\mathrm{Cu},{ }^{11-15}$ ruthenium oxide, ${ }^{15-18}$ and platinum surface. ${ }^{19-20}$ The main electrolytes used for copper electrodeposition are solutions containing sulfates, ${ }^{1-7,9,10,13,14,19,21,22}$ pyrophosphate, ${ }^{23}$ fluoroborate, ${ }^{24}$ nitrates,,${ }^{9,25}$ chlorides ${ }^{25}$ and perchlorates. ${ }^{17,26}$ In general, an instantaneous copper nucleation mechanism has been identified; however from fluoroborate and sulfates solutions it has been reported a progressive nucleation mechanism. ${ }^{27}$ Also, an island growth can occur in the kinetic regime. ${ }^{17}$ In summary, it was evidenced that the type of copper nucleation mechanism depends on the $\mathrm{pH}$ of solution, the supporting electrolyte and the substrate. ${ }^{3}$

Although the anion effect is well known, only few studies have been reported considering the influence of the $\mathrm{ClO}_{4}{ }^{-}$anion during the copper electrodeposition. ${ }^{17,26}$ It is interesting to note that the perchlorate anions generally interact weaker with the electrode surfaces than anions such as (bi)-sulfate anions. ${ }^{28,29}$ Thus, the use of an electrolyte based on perchlorates allows to study the nucleation process without a strong interference of anions adsorbed on the substrate. Additionally, the main advantage of using carbon electrodes in the electrodeposition studies is that as it is an inert substrate and it is possible to study the nucleation and growth neglecting the metal-metal interaction. On the other hand, copper electrodeposition on highly oriented pyrolytic graphite electrodes (HOPGE) has been less studied in comparison with glassy carbon electrodes (GCE). ${ }^{8-10}$ Additionally, up to our knowledge, a comparison between the kinetic parameters of copper electrodeposition from perchlorate baths onto GCE and HOPGE is missing. Thus, in this paper, a kinetical study of the copper

*e-mail: hhuizar@uaeh.edu.mx electrodeposition onto GCE and HOPGE from perchlorate baths is examined. Electrochemical techniques such as cyclic voltammetry and chronoamperometry were employed.

\section{EXPERIMENTAL}

Copper electrodeposits onto GCE and HOPGE were carried out from an aqueous solution containing $0.01 \mathrm{M} \mathrm{Cu}\left(\mathrm{ClO}_{4}\right)_{2}+0.02 \mathrm{M} \mathrm{NaClO}_{4}$ at $\mathrm{pH}=5$. All solutions were prepared using analytic grade reagents with ultra pure water (Millipore-Q system) and were deoxygenated by bubbling $\mathrm{N}_{2}$ for 15 min before each experiment. The working electrodes were a GCE tip provided by BAS ${ }^{\mathrm{TM}}$, with $0.071 \mathrm{~cm}^{2}$ of area and a freshly cleaved HOPGE surfaces. In the case of GCE, the exposed surface was polished to a mirror finish with different grades of alumina down to $0.05 \mu \mathrm{m}$ and ultrasonically cleaned before experiments. A graphite bar with an exposed area greater than the working electrode was used as counter electrode. A saturated calomel electrode (SCE) was used as reference electrode, and all measured potentials are referred to this scale. All experiments were carried out at $25^{\circ} \mathrm{C}$. The electrochemical experiments were carried out in a Epsilon potentiostat connected to a personal computer running the BASi-Epsilon-EC software to allow the control of experiments and data acquisition. In order to verify the electrochemical behavior of the electrode in the electrodeposition bath, cyclic voltammetry was performed in the [0.6 - -0.7] V potential range. The kinetic mechanism of copper deposits onto GCE and HOPGE was studied under potentiostatic conditions by means of the analysis of the experimental current density transients obtained with the potential step technique. The perturbation of the potential electrode always started at $0.600 \mathrm{~V}$. The potential step was imposed at different potentials detailed in this work.

\section{RESULTS AND DISCUSSION}

\section{Voltammetric study}

Under stationary conditions, the copper electrodeposition has been interpreted as occurring in two elementary steps, each of which 
involves the transfer of an electron, following the next reactions: ${ }^{30}$

$$
\begin{gathered}
C u^{2+}+e^{-} \underset{k_{-1}}{\stackrel{k_{1}}{\Leftrightarrow}} C u^{+} \\
C u^{+}+e^{-} \underset{k_{-2}}{\Leftrightarrow} C u^{0}
\end{gathered}
$$

where the first step is much slower than the second one ${ }^{30}$ From voltammetric studies, it is possible to identify the existence of these two elementary steps represented by Reactions 1 and $2 .{ }^{5}$ Thus, in order to identify the presence of these steps in our systems we carried out a voltammetric study. Figure 1 shows the voltammetric response, at the scan rate of $20 \mathrm{mVs}^{-1}$, obtained from $0.01 \mathrm{M} \mathrm{Cu}\left(\mathrm{ClO}_{4}\right)_{2}+$ $0.02 \mathrm{M} \mathrm{NaClO}_{4}$ at $\mathrm{pH}=5$ onto GCE (system I) and HOPGE (system II) substrates.

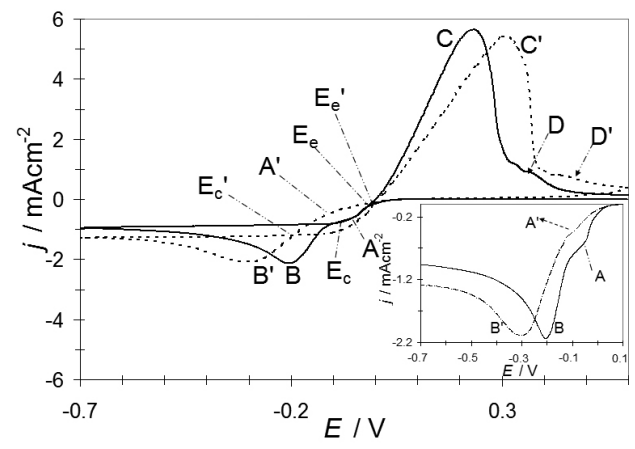

Figure 1. A comparison of two cyclic voltammetric curves obtained in the GCE (solid line) and HOPGE (broken line) from an aqueous solution 0.01M $\mathrm{Cu}\left(\mathrm{ClO}_{4}\right)_{2}+0.02 \mathrm{NaClO}_{4}(\mathrm{pH}$ 5.0). The potential scan rate was started at $0.600 \mathrm{~V}$ toward the negative direction with a potential scan rate of $20 \mathrm{mV} \mathrm{s}^{-1}$

At direct scan it may be observed that the $\mathrm{Cu}$ electrodeposition starts at $0.020 \mathrm{~V}$ approximately. Note at $-0.050 \mathrm{~V}$ the presence of a peak (A and A') in both substrates, see inset in Figure 1, this peak has been associated to a slow electronic transfer process according to Reaction $1,{ }^{5}$ while peaks B and B' have been associated to Reaction 2. During the inverse of the potential scan, it was recorded a crossover $E_{\mathrm{c}}$ at $-0.093 \mathrm{~V}$ and $E_{\mathrm{e}}-0.002 \mathrm{~V}$ for GCE while the values of $E_{\mathrm{c}}$ ' and $E_{\mathrm{e}}$ for HOPGE were -0.192 and $-0.006 \mathrm{~V}$ respectively. Crossover potential $E_{\mathrm{c}}$ and $E_{\mathrm{c}}$ ' have been associated to an electrocatalytic point. ${ }^{31}$ In some cases, the crossoverpotentials $E_{\mathrm{e}}$ and $E_{\mathrm{e}}$ ' may be associated to the thermodynamical potential of $\mathrm{M}^{\mathrm{n}+} / \mathrm{M}$, only when this cross is independent of the switch potential $\left(E_{\lambda}\right)$ (and only when $E_{\lambda}$ is less negative of the corresponding peak potential. ${ }^{32}$ However, this was not the case for the crossovers $E_{\mathrm{e}}$ and $E_{\mathrm{e}}$. In the anodic zone, it was possible to observe two principal peaks $C$ and $C^{\prime}$ at around 0.233 and $0.320 \mathrm{~V}$, respectively. Shoulders D and D' were recorded at 0.368 and $0.460 \mathrm{~V}$, respectively. Peak C and C' may be associated to the dissolution of metallic copper to cupric ions according to the following reaction: ${ }^{5}$

$$
\mathrm{Cu}^{0}+6 \mathrm{H}_{2} \mathrm{O} \Leftrightarrow \mathrm{Cu}\left(\mathrm{H}_{2} \mathrm{O}\right)_{6}^{2+}+2 e
$$

While the shoulder D and D' has been associated to the chemical reaction between the cupric ions accumulated on the surface and the remainder of metallic copper as it is represented in Equations 4 and 5:5

$$
\begin{gathered}
\mathrm{Cu}^{0}+\mathrm{Cu}\left(\mathrm{H}_{2} \mathrm{O}\right)_{6}^{2+}+2 \mathrm{H}_{2} \mathrm{O} \Leftrightarrow 2 \mathrm{Cu}\left(\mathrm{H}_{2} \mathrm{O}\right)_{4}^{+} \\
\mathrm{Cu}\left(\mathrm{H}_{2} \mathrm{O}\right)_{4}^{+}+2 \mathrm{H}_{2} \mathrm{O} \Leftrightarrow \mathrm{Cu}\left(\mathrm{H}_{2} \mathrm{O}\right)_{6}^{2+}+e
\end{gathered}
$$

To ensure that the peaks A and A' are not associated to an underpotential deposition process, we perform a scan potential in upd copper zone and a stripping of the probable deposit obtained in upd conditions was not observed. In order to find out the kind of control that limits the copper electrodeposition process associated with peak $\mathrm{B}$, the current density value associated $\left(j_{\mathrm{p}}\right)$ was plotted as a function of $v^{1 / 2}$ according to the Berzins-Delahay's Equation, (6): $:^{33}$

$$
j_{p}=\frac{i_{p}}{S}=367 n^{3 / 2} C_{0} D^{1 / 2} v^{1 / 2}
$$

in this equation $i_{\mathrm{p}}$ is the peak current value in Amperes, $n$ is the number of electrons transferred, $S$ is the area in $\mathrm{cm}^{2}, C_{\mathrm{o}}$ is the molar concentration in the bulk, $D$ is the diffusional coefficient $\mathrm{cm}^{2} \mathrm{~s}^{-1}$, and $v$ is the potential scan rate in $\mathrm{V} \mathrm{s}^{-1}$. A linear relationship of $j_{\mathrm{p}} \mathrm{vs} v^{1 / 2}$ was found in both systems which suggests a copper diffusional control process associated with peak B and B', Figure 2.

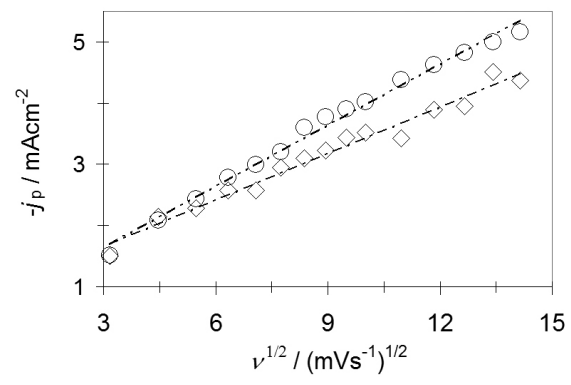

Figure 2. Plot of the experimental cathodic peak current density $B(O)$ and $B^{\prime}(\diamond)$ as a function of scan rate $\left(\mathrm{v}^{1 / 2}\right)$. The straight line corresponds to the linear fit of the experimental data according to Equation 6

\section{Cronoamperometry study}

Formation of new phases generally occurs through nucleation and growth mechanisms and the corresponding current transients can provide valuable information about the kinetics of electrodeposition process. Figure 3 shows a set of current density transients recorded at different potentials by a step potential technique.

These transients were obtained by applying an initial potential of $0.600 \mathrm{~V}$ on the surface of the GCE and HOPGE electrodes. At this potential value, the $\mathrm{Cu}$ deposition had not still begun. After the application of this initial potential, a step of negative potential was varied on the surface of the electrode. Once the current maximum has been reached, a decay of the current was obtained. From the transients showed in Figure 3, note that the copper electrodeposition process is slightly more favored on the GCE substrate because in the same overpotential the current maximum is reached at lesser times in comparison with the obtained on HOPGE. Probably, the electrodeposition process on GCE is favored because there are more structural defects that favor the nucleation process. Apparently, the general shape of these transients is very similar to those reported for a three dimensional nucleation process with diffusion control (3D-dc). ${ }^{34,35} \mathrm{~A}$ classification of the nucleation as instantaneous or progressive from transients showed in Figure 3 is possible by following the criteria established by Sharifker et al. where the experimental transients in a non-dimensional form by plotting $j^{2} / j_{\mathrm{m}}{ }^{2} \mathrm{vs} t / t_{\mathrm{m}}$ are compared with those theoretically generated from Equations 7 and 8 for instantaneous and progressive nucleation, respectively. ${ }^{34}$

$$
\frac{j^{2}}{j_{m}^{2}}=1.9254\left(\frac{t}{t_{m}}\right)^{-1}\left\{1-\exp \left[-1.2564\left(\frac{t}{t_{m}}\right)\right]\right\}^{2}
$$


a) GCE

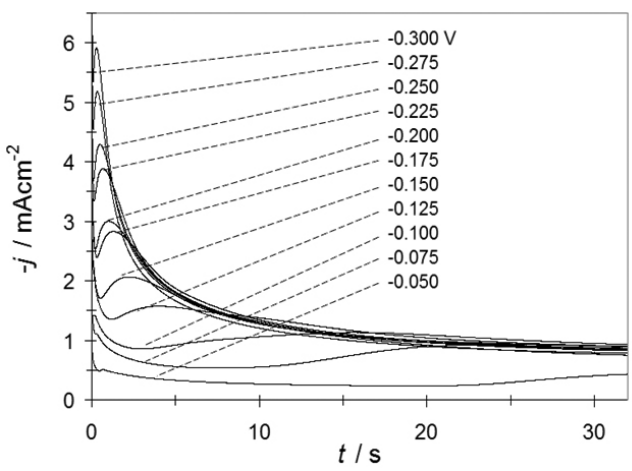

b) HOPGE

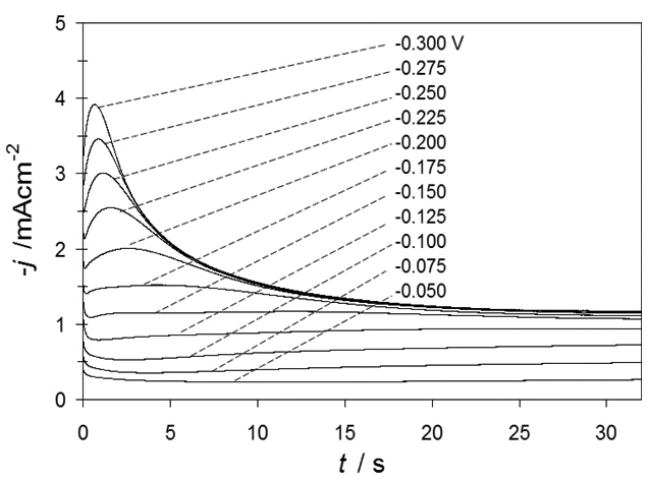

Figure 3. A set of current transients obtained from aqueous solution $0.01 \mathrm{M}$ $\mathrm{Cu}\left(\mathrm{ClO}_{4}\right)_{2}+0.02 \mathrm{NaClO}_{4}(\mathrm{pH}=5)$ on a) GCE and b) HOPGE by means of the potential step technique for different potential step values $(\mathrm{mV})$ indicated in the figure. In all the cases, the initial potential was $0.600 \mathrm{~V}$

$$
\frac{j^{2}}{j_{m}^{2}}=1.2254\left(\frac{t}{t_{m}}\right)^{-1}\left\{1-\exp \left[-2.3367\left(\frac{t}{t_{m}}\right)^{2}\right]\right\}^{2}
$$

where $j_{\mathrm{m}}$ is the current density on the maximum reached at the time $t_{\mathrm{m}}$.

Figure 4 shows a comparison of a theoretical dimensionless transient, generated by Equations 7 and 8 with the experimental dimensionless current transient reported in Figure 3, similar results were obtained for the others experimental transients. It is important to mention that from these plots it was not possible to classify the nucleation process as instantaneous or progressive. Here, it must be reminded that the theoretical curves generated by Equations 7 and 8 correspond to two extreme cases of the nucleation process and in some cases a classification is not possible. From the plots, note that in both systems, the experimental current density is major that the predicted by the theoretical dimensionless transients, which may be caused by the existence of an additional process which in turn may be associated with the proton reduction process. In general, the effect of hydrogen co-deposition during metal electrodeposition process can be evidenced through the direct observation of hydrogen bubbles which cling to the surface in an adsorbed state. ${ }^{36}$ In our case, at higher overpotentials than $300 \mathrm{mV}$, we could observe the presence of small dispersed bubbles on the electrodes which may be associated to hydrogen evolution on the electrode. It is important to mention that at lower overpotentials than $300 \mathrm{mV}$, these bubbles were not observed. Thus, under our experimental conditions, convection problems due to the formation of $\mathrm{H}_{2}$ bubbles may be considered negligible because no $\mathrm{H}_{2}$ bubbles were noticed to form during the recording of the experimental current-time transients.

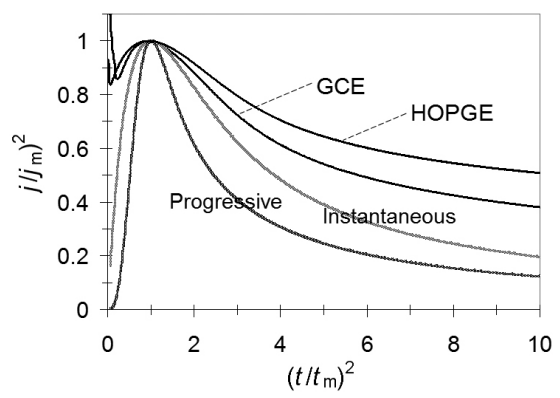

Figure 4. Comparison of an experimental transient obtained at $-225 \mathrm{mV}$, normalized through the coordinates of its respective local maximum $\left(t_{m}, j_{m}\right)$, with the theoretical non-dimensional curves corresponding to $3 D$ instantaneous nucleation (Equation 7) and 3D progressive nucleation (Equation 8)

\section{Analysis of the transients}

Milchev et al. have found that for copper electrodeposition process on GCE, the falling currents observed at short times must be related to the copper ions discharge. ${ }^{4}$ Since the last process is known to take place in two steps as it is represented by Reactions 1 and $2 .{ }^{5}$ Under these conditions the slow step (Equation 1) may lead to the accumulation of $\mathrm{Cu}^{+}$at the electrode surface if the nucleation and growth of copper cluster is not sufficiently fast. ${ }^{4,5}$ According with Milchev et al., the electron transfer reaction takes place prior to and simultaneously with the process of the nucleus formation. ${ }^{4,5}$ Thus, the current density associated to these processes, before the nuclei overlapping is given by: 4,5

$$
j_{M}=a_{R} \exp \left(-b_{R} t\right)+q\left[(1+2 n t)^{1 / 2}-1\right]^{3}
$$

where

$$
\begin{gathered}
a_{R}=a_{R}^{0} \exp \left(\frac{-\alpha_{e} z F E}{R T}\right) \\
b_{R}=\omega_{R}^{0} \exp \left(\frac{-\alpha_{e} z F E}{R T}\right)+\omega_{O}^{0} \exp \left(\frac{\left(1-\alpha_{e}\right) z F E}{R T}\right) \\
q=\frac{s \pi F^{4}(D C)^{3}}{j_{0} V_{M}} I_{s t} \exp \left(\frac{-3 \alpha F \eta}{R T}\right)
\end{gathered}
$$

with

$$
n=\frac{v i_{0} V_{M} Q}{F^{2} D C}
$$

with $\mathrm{s}=32 / 3, \mathrm{v}=1 / 4$ and

$$
Q=\exp \left(\frac{2 \alpha F \eta}{R T}\right)-\exp \left[\frac{-2(1-\alpha) F \eta}{R T}\right]
$$

where $j_{0}$ is the exchange current density at the "copper-solution" interface, $\eta$ the overpotential, $I_{\mathrm{st}}$ the stationary nucleation rate, $V_{\mathrm{M}}$ is the molar volume, $\alpha_{\mathrm{e}}$ is the electron transfer coefficient, the value of which follows from the Marcus theory, $a_{O}^{R}, \omega_{O}^{R}$ and $\omega_{O}^{0}$ are potential independent quantities and $z=1 ., 5 \mathrm{It}$ is important to mention that for copper electrodeposition, the reaction $\mathrm{Oxy}+z e^{-} \leftrightarrow$ Red coincided with the slow step (Equation 1) of the overall copper ions' discharge and should be considered as a single electron transfer reaction. ${ }^{4}$ Therefore, in these conditions $\alpha$ has the same meaning of symmetry factor. ${ }^{37}$ All other parameters have their conventional meaning. The first term in Equation 9 is related with an electron transfer reaction, while the second term describes the current of progressive nucleation 
and growth of the copper crystals on the substrate, under combined "charge transfer" and "diffusion limitations". ${ }^{4,5}$ In order to evaluate the applicability of Milchev's model, in present work it was applied the model to potentiostatic curves obtained at low overpotentials and short times, ensuring that any overlapping and coalescence of the clusters do not occur during the growth. In this analysis, not shown, the model proposed by Milchev et al., could not account for the transient behavior at times bigger than $1 \mathrm{~s}$. Thus, the proton reduction process must be taken into account to perform a well prediction of the general behavior of the transients. It has been proposed that when the proton reduction occurs simultaneously with the diffusion-limited 3D growth of metallic centers, the overall current density is given by: ${ }^{38}$

$$
\begin{gathered}
j_{3 D}(t)=\left\{P_{1}^{*}+P_{4} t^{-1 / 2}\right\} \times\left\{1-\exp \left[t-\frac{1-\exp \left(-P_{3} t\right)}{P_{3}}\right]\right\} \\
P_{1}^{*}=P_{1}\left(\frac{2 c M}{\pi \rho}\right)^{1 / 2} \\
P_{1}=z_{P R} F k_{P R} \\
P_{2}=N_{0} \pi k D \\
P_{3}=A \\
P_{4}=\frac{2 F D^{1 / 2} c}{\pi^{1 / 2}} \\
k=\left(\frac{8 \pi c}{\rho}\right)^{1 / 2}
\end{gathered}
$$

where $z_{P R} F$ is the molar charge transferred during the proton reduction process, $k_{P R}$ is the rate constant of the proton reduction reaction, $N_{0}$ is the number of active nucleation sites, $A$ is the nucleation rate, $D$ is the diffusion coefficient, $F$ is the Faraday's constant and all others parameters have their conventional meanings.

Thus, considering the different contributions during the copper electrodeposition in the present work we propose that the current density recorded during the experiments may be explained considering an electron transfer, a 3D nucleation and growth process of copper and a proton reduction process. Additionally, it is taken into account the evidence shown by Hozle et al. that apart from the nucleation processes, there is an adsorption stage associated with the double layer charging process. ${ }^{39}$ Therefore, we propose that the experimental current density transients $\left(j_{\mathrm{T}}\right)$ obtained during copper electrodeposition on carbon substrates may be described by means of Equation 22 .

$$
j_{T}=k_{1} \exp \left(-k_{2} t\right)+a_{R} \exp \left(-b_{R} t\right)+j_{3 D}(t)
$$

Figure 5 shows a typical comparison of the experimental reduction current transients, with the theoretically generated by non-linear fitting of experimental data to Equation 22.

It can be observed that the model expressed by this equation adequately accounted for the behavior of experimental transient. The physical parameters obtained from the adjustments of Equation 22 are summarized for GCE (Table 1) and for HOPGE (Table 2).

Note that the average diffusion coefficient calculated from the fittings in both systems was $6.3 \times 10^{-6} \mathrm{~cm}^{2} \mathrm{~s}^{-1}$, this value compare favorably with those values reported in the literature, which vary over a range of $1.2 \times 10^{-6}-6.8 \times 10^{-6} \mathrm{~cm}^{2} \mathrm{~s}^{-1} \cdot{ }^{13,40-43}$ Also, observe the overpotential dependence of $a_{\mathrm{R}}$ (Equation 10), it is possible to calculate a value of 0.24 and 0.21 for $\alpha$ from the slope $\mathrm{d}\left(\ln a_{\mathrm{R}}\right) / \mathrm{d} E$ of the resulting linear $\ln a_{\mathrm{R}}(E)$ plot for GCE and HOPGE respectively.

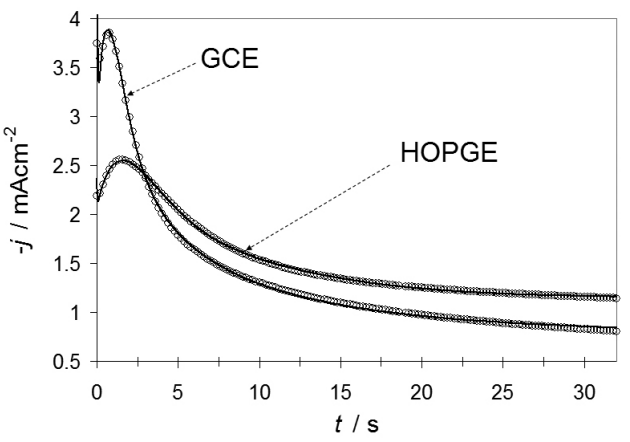

Figure 5. Comparison between an experimental current density transients (-) recorded during the copper electrodeposition onto GCE and HOPGE

\begin{tabular}{|c|c|c|c|c|c|c|}
\hline$E / \mathrm{V}$ & $a_{\mathrm{R}} / \mathrm{mA}$ & $b_{\mathrm{R}} / \mathrm{s}^{-1}$ & $\begin{array}{c}k_{\mathrm{PR}} \mathrm{X} 10^{6} / \\
\mathrm{mol} \mathrm{cm} \mathrm{cm}^{-2} \mathrm{~s}^{-1}\end{array}$ & $\begin{array}{c}D X 10^{6} / \\
\mathrm{cm}^{2} \mathrm{~s}^{-1}\end{array}$ & $A / \mathrm{s}^{-1}$ & $\begin{array}{c}N_{0} \mathrm{X} 10^{-4} \\
/ \mathrm{cm}^{-2}\end{array}$ \\
\hline-0.050 & 0.53 & 0.10 & 5.78 & 5.27 & 0.05 & 0.01 \\
\hline-0.075 & 1.18 & 0.28 & 6.05 & 6.15 & 0.17 & 0.26 \\
\hline-0.100 & 1.48 & 0.46 & 5.05 & 6.15 & 0.41 & 0.62 \\
\hline-0.125 & 1.49 & 0.46 & 4.68 & 6.15 & 1.04 & 1.96 \\
\hline-0.150 & 1.92 & 0.47 & 3.91 & 6.15 & 1.10 & 2.54 \\
\hline-0.175 & 2.75 & 0.43 & 4.00 & 6.15 & 1.26 & 2.54 \\
\hline-0.200 & 2.84 & 0.49 & 2.92 & 7.09 & 1.87 & 2.60 \\
\hline-0.225 & 3.59 & 0.62 & 3.42 & 7.09 & 5.35 & 2.90 \\
\hline-0.250 & 3.90 & 0.63 & 3.96 & 6.25 & 14.45 & 2.62 \\
\hline-0.275 & 5.11 & 0.95 & 3.94 & 5.91 & 19.46 & 3.10 \\
\hline-0.300 & 5.78 & 1.03 & 3.96 & 6.80 & 29.12 & 3.35 \\
\hline
\end{tabular}
electrodes when a potential value of -0.225 V was applied with a theoretical transient $(O)$ generated by non-linear fitting of Equation 22

Table 1. Potential dependence for the physical constants involved during copper electrodeposition on $\mathrm{GCE}$ from $0.01 \mathrm{M} \mathrm{Cu}\left(\mathrm{ClO}_{4}\right)_{2}+0.02 \mathrm{M} \mathrm{NaClO}_{4}$ solution. The values were obtained from best-fit parameters found through the fitting process of the experimental $\mathrm{j}$-t plots using Equation 22

\begin{tabular}{|c|c|c|c|c|c|c|}
\hline$E / \mathrm{V}$ & $a_{\mathrm{R}} / \mathrm{mA}$ & $b_{\mathrm{R}} / \mathrm{s}^{-1}$ & $\begin{array}{c}k_{\mathrm{PR}} \mathrm{X} 10^{6} / \\
\mathrm{mol} \mathrm{cm} \mathrm{cm}^{-2} \mathrm{~s}^{-1}\end{array}$ & $\begin{array}{c}D \times 10^{6} / \\
\mathrm{cm}^{2} \mathrm{~s}^{-1}\end{array}$ & $A / \mathrm{s}^{-1}$ & $\begin{array}{c}N_{0} \mathrm{X} 10^{-4} / \\
\mathrm{cm}^{-2}\end{array}$ \\
\hline-0.050 & 0.31 & 0.07 & 1.01 & 6.15 & 0.06 & 0.12 \\
\hline-0.075 & 0.41 & 0.10 & 1.03 & 6.61 & 0.10 & 0.15 \\
\hline-0.100 & 0.63 & 0.20 & 3.33 & 6.15 & 0.25 & 0.22 \\
\hline-0.125 & 0.87 & 0.18 & 5.44 & 6.15 & 0.37 & 0.26 \\
\hline-0.150 & 1.19 & 0.26 & 6.11 & 6.15 & 0.67 & 0.44 \\
\hline-0.175 & 1.49 & 0.19 & 6.24 & 6.15 & 1.03 & 0.55 \\
\hline-0.200 & 1.82 & 0.31 & 6.45 & 6.15 & 1.48 & 1.13 \\
\hline-0.225 & 2.19 & 0.37 & 6.45 & 6.32 & 2.74 & 1.57 \\
\hline-0.250 & 2.60 & 0.41 & 6.45 & 6.15 & 5.38 & 1.86 \\
\hline-0.275 & 2.91 & 0.49 & 6.45 & 6.42 & 7.51 & 2.28 \\
\hline-0.300 & 3.24 & 0.58 & 6.45 & 6.75 & 11.76 & 2.72 \\
\hline
\end{tabular}

\section{GCE}

Table 2. Potential dependence for the physical constants involved during copper electrodeposition on HOPGE from $0.01 \mathrm{M} \mathrm{Cu}\left(\mathrm{ClO}_{4}\right)_{2}+0.02 \mathrm{M} \mathrm{NaClO}_{4}$ solution. The values were obtained from best-fit parameters found through the fitting process of the experimental $j$ - $t$ plots using Equation 22

HOPG 
From the physical parameters obtained (Tables 1 and 2), it is seen that an increment of the $A$ and $N_{0}$ is obtained when the overpotential applied is increased. Also, note that the values of $A$ and $N_{0}$ are bigger for GCE than for HOPGE. This may be caused by the existence of better energy surface conditions on GCE. The $k_{\mathrm{PR}}$ values did not show a clear tendency on GCE, however on HOPGE it was observed an increase in their values indicating that the reduction proton process is favored and suggesting a competition by the active sites on the surface by a co-deposition process of $\mathrm{H}^{+}$ions with the $\mathrm{Cu}$ cations.

In the framework of the atomistic theory of electrolytic nucleation, it is possible to estimate the critical size of the $\mathrm{Cu}$ nucleus $\left(n_{c}\right)$ from the potential dependence of $A$ through the Equation $23:{ }^{44}$

$$
n_{c}=\left(\frac{k_{B} T}{z e_{0}}\right)\left(\frac{d \ln A}{d \eta}\right)-\alpha_{C u}
$$

where $\alpha_{C u}$ is the transfer coefficient for $\mathrm{Cu}$ reduction. The plots $\mathrm{ln}$ $A$ vs $\eta$ showed a linear tendency for both substrates, Figure 6 . By substituting the values of $\mathrm{d} \ln \mathrm{A} / \mathrm{dE}$ in Equation 23, 24.02 and 21.2 for GCE and HOPGE respectively and by considering the values of $\alpha$ found in this study, it was obtained $n_{\mathrm{c}}=1$ for both substrates, this value mean that each active site is a critical nucleus within the whole investigated overpotential interval. This value compare favorably with the obtained by Milchev et al. for the copper electrodeposition on GCE from sulfate solutions. ${ }^{5}$

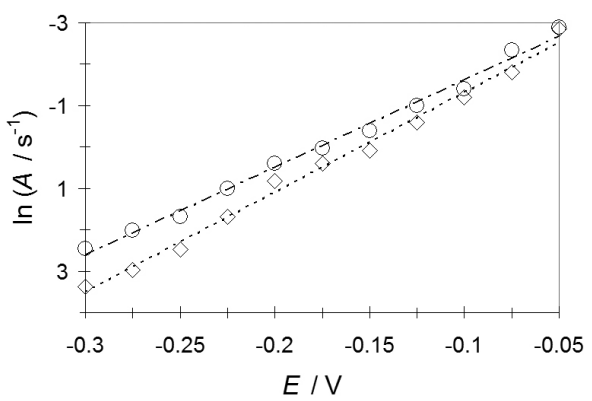

Figure 6. In A vs E plot used to calculate the critical nuclei's size according to Equation 23. GCE $(O)$ and $H O P G E(\diamond)$

\section{CONCLUSIONS}

In present work copper electrodeposition on carbon substrates (GCE and HOPGE) was analyzed employing electrochemical techniques. Cyclic voltammetry study showed the presence of an electronic transfer step. From the potentiostatic study it was possible to evaluate the nucleation and growth parameters employing a nucleation model that involves four different contributions: a Langmuir type adsorption process, an electron transfer from $\mathrm{Cu}^{2+} \rightarrow \mathrm{Cu}^{+}$, a 3D nucleation limited by a mass transfer reaction and a proton reduction process. The values of $A$ and $N_{0}$ were increased on GCE with the increment of the overpotential applied. The values of the rate constant of the proton reduction $\left(k_{P R}\right)$ on GCE and HOPGE were, in average, $4.33 \times 10^{-7}$ $\mathrm{mol} \mathrm{cm} \mathrm{s}^{-2}$ and $5.04 \times 10^{-7} \mathrm{~mol} \mathrm{~cm}^{-2} \mathrm{~s}^{-1}$ respectively.

\section{ACKNOWLEDGMENTS}

DEGR is grateful for a graduate student fellowship from CONACyT. CHRR is grateful for a postdoctoral fellowship from CONACyT. We gratefully acknowledge financial support from the Universidad Autónoma del Estado de Hidalgo. We are also grateful to the reviewers of the manuscript for valuable suggestions.

\section{REFERENCES}

1. Danilov, A. I.; Molodokina, E. B.; Polukarov, Y. M.; Russ. J. Electrochem. 2002, 38, 732.

2. Grujicic, D.; Pesic, B.; Electrochim. Acta 2002, 47, 2901.

3. Grujicic, D.; Pesic, B.; Electrochim. Acta 2005, 50, 4426.

4. Milchev, A.; Zapryanova, T.; Electrochim. Acta 2006, 51, 4916.

5. Milchev, A.; Zapryanova, T.; Electrochim. Acta 2006, 51, 2926.

6. Zapryanova, T.; Hrussanova, A.; Milchev, A.; J. Electroanal. Chem. 2007, 600, 311 .

7. Zapryanova, T.; Jordanov, N.; Milchev, A.; J. Electroanal. Chem. 2008, 612, 47.

8. Liu, H.; Favier, F.; Ng, K.; Zach, M. P.; Penner, R. M.; Electrochim. Acta 2001, 47, 671.

9. Ghodbanea, O.; Roue, L.; Belanger, D.; Electrochim. Acta 2007, 52, 5843.

10. Huanga, L.; Lee, E. S.; Kim, K. B.; Colloids Surf. A 2005, 262, 125 .

11. Brisard, G.; Bertrand, N.; Ross, P. N.; Markovic, N. M.; J. Electroanal. Chem. 2000, 480, 219.

12. Dube, P.; Brisard, G. M.; J. Electroanal. Chem. 2005, 582, 230.

13. Pasquale, M. A.; Gassa, L. M.; Arvia, A. J.; Electrochim. Acta 2008, 53, 5891.

14. Varvara, S.; Muresan, L.; Popescu, I. C.; Maurin, G.; Hydrometallurgy 2004, 75, 147.

15. Guo, L.; Radisic, A.; Searson, P. C.; J. Electrochem. Soc. 2006, 153, C840.

16. Guo, L.; Zhang, S. L.; Searson, P.; Phys. Rev. E: Stat., Nonlinear, Soft Matter Phys. 2009, 79, 51601.

17. Guo, L.; Thompson, A.; Searson, P. C.; Electrochim. Acta 2010, 55, 8416.

18. Stuve, E. M.; Rogers, W.; Ingersoll, D.; Goodman, D. W.; Thomas, M. L.; Paffett, M. T.; Chem. Phys. Lett. 1985, 149, 557.

19. Quinet, M.; Lallemand, F.; Ricq, L.; Hihn, J. Y.; Delobelle, P.; Surf. Coat. Technol. 2010, 204, 3108.

20. Quinet, M.; Lallemanda, F.; Ricq, L.; Hihna, J. Y.; Delobelle, P.; Arnould, C.; Mekhalif, Z.; Electrochim. Acta 2009, 54, 1529.

21. Nikolic, N. D.; Pavlovic, L. J.; Pavlovic, M. G.; Popov, K. I.; Electrochim. Acta 2007, 52, 8096.

22. Fernández, D.; Coey, J. M. D.; Electrochem. Commun. 2009, 11,379 .

23. Radisic, J. G.; Long, P. M.; Hoffmann, P. C.; Searson, P. C.; J. Electrochem. Soc. 2001, 148, C41.

24. Nila, C.; Gonzalez, I.; J. Electroanal. Chem. 1996, 401, 171.

25. Ramos, M. M.; Hernandez, T.; Gonzalez, I.; J. Electrochem. Soc. 2001, 148, C315.

26. Lei, J.; Rudenja, S.; Magtoto, N.; Kelber, J. A.; Thin Solid Films 2006, 497, 121.

27. Oskam, G.; Vereecken, P. M.; Searson, P. C.; J. Electrochem. Soc. 1999, 146, 143.

28. El-Aziz, A. M.; Kibler, L. A.; Electrochem. Commun. 2002, 4, 866.

29. Lu, P. C.; Yang, C. H.; Yau, S. L.; Zei, M. S.; Langmuir 2002, $18,754$.

30. Mattsson, E.; Bockris, J. O. M.; Trans. Faraday Soc. 1960, 55, 1586.

31. Greef, R.; Peat, R.; Peter, L. M.; Pletcher, D.; Robinson, J.; Instrumental Methods in Electrochemistry, Ellis Horwood: Chichester, 1985, ch. 9 .

32. Rojas-Hernández, A.; Ramírez, T. M.; Ibáñez, J. G.; González, I.; J. Electrochem. Soc. 1991, 138, 365.

33. Berzins, T.; Delahay, P.; J. Am. Chem. Soc. 1953, 75, 555.

34. Scharifker, B. R.; Hills, G.; Electrochim. Acta 1983, 28, 879. 
35. Scharifker, B. R.; Mostany, J.; J. Electroanal. Chem. 1984, $177,13$.

36. Gabe, D. R.; J. Appl. Electrochem. 1997, 27, 908.

37. Bockris, J. O.; Reddy, A. K. N.; Gamboa-Aldeco, M.; Modern Electrochemistry 2A, Fundamentals of Electrodics, $2^{\text {nd }}$ ed.; Kluwer Academic Publishers: New York, 2000, ch. 7.

38. Palomar-Pardavé, M.; Scharifker, B. R.; Arce, E. M.; RomeroRomo, M.; Electrochim. Acta 2005, 50, 4736.
39. Holzle, M. H.; Retter, U.; Kolb, D. M.; J. Electroanal. Chem. 1994, 371, 101.

40. Farndon, E. E.; Walsh, F. C.; Campbell, S. A.; J. Appl. Electrochem. 1995, 25, 574.

41. Lenoir, F.; Wiart, R.; Industrie 1972, 557, 1.

42. Moats, M. S.; Hiskey, J. B.; Collins, D. W.; Hydrometallurgy 2000, 56, 255.

43. Quickenden, T. I.; Jiang, X.; Electrochim. Acta 1984, 29, 693.

44. Milchev, A.; J. Contemp. Phys. 1991, 32, 321. 